\title{
An enquiry into Investment Control of Engineering Projects
}

\author{
Huilin Chen ${ }^{1, \mathrm{a}^{*}}$ \\ ${ }^{1}$ Logistics Department, Wuhan University of Technology, Wuhan, Hubei, 430070
}

\begin{abstract}
The relatively weak link in the current construction project management is the project investment control. There is often a lack of accurate investigation beforehand and the lack of real investigation data, resulting in the lack of authenticity of the investigation report, and it is difficult to calculate the investment spent on the project. Engineering projects are prone to investment risks and cause unnecessary losses. Construction project investment is related to the future development trend of the construction industry. In order to adapt to the development needs of the society, this article discusses current engineering projects from the four key aspects of project investment control—optimized design, good bidding, scientific management, and strengthening of audits. There are problems in the investment process, and the corresponding investment control strategies are discussed. The research conclusions show that these four key aspects play a very important role in engineering project investment control.
\end{abstract}

\section{Introduction}

The investment control of engineering construction projects is one of the important tasks of the construction economy, and it plays a pivotal role in the country's economic construction and development. In the more than 20 years of reform and opening up, while our country's economic construction has made brilliant achievements, engineering project investment control has also made remarkable achievements. Practice has proved that to do a good job in engineering construction project investment control work requires not only professional personnel with high professional quality in construction project investment control, but also comprehensive and focused control of the whole process.

At present, engineering project investment is facing many problems. Most of engineering project investment control uses plan control, and the overall quality of cost management personnel is somewhat different. In the process of cost auditing, many companies are in line with the development needs of today's society, and the engineering contract lacks correctness. The management of engineering contracts has not attracted enough attention. Many engineering contracts have many loopholes, and standardized management cannot be implemented. Investment control is in a passive state. It is difficult to implement full control over the process of all engineering projects [1]. There are still many problems in the development process of engineering project investment control. Combining the characteristics of the industry, it is very important to improve the management system. Only by truly improving the system of engineering project investment control can the project investment be well controlled. The industry can truly flourish.

Combining many years of investment control work, the author talks about my own thoughts on the four key aspects of investment control optimization design, doing a good job in bidding, scientific management, and strengthening auditing.

\section{Optimizing design}

It is shown that the possibility of project decision as well as design affecting project investment is between $30 \%$ and $75 \%$, while that of construction is between $5 \%$ and $25 \%$ [2]. Thus, it is obvious that the stage of decision and design is the key stage of investment control. After decision, the key to investment control lies in scientific design. Once the design drawing is finished, the project's structure, decoration standard and selection of materials and equipment will be determined and thus investment amount will be determined. Figure 1 shows the impact curve of the project's life cycle stage on investment.

\footnotetext{
*Corresponding author: ${ }^{2} 291445 @$ whut.edu.cn
} 


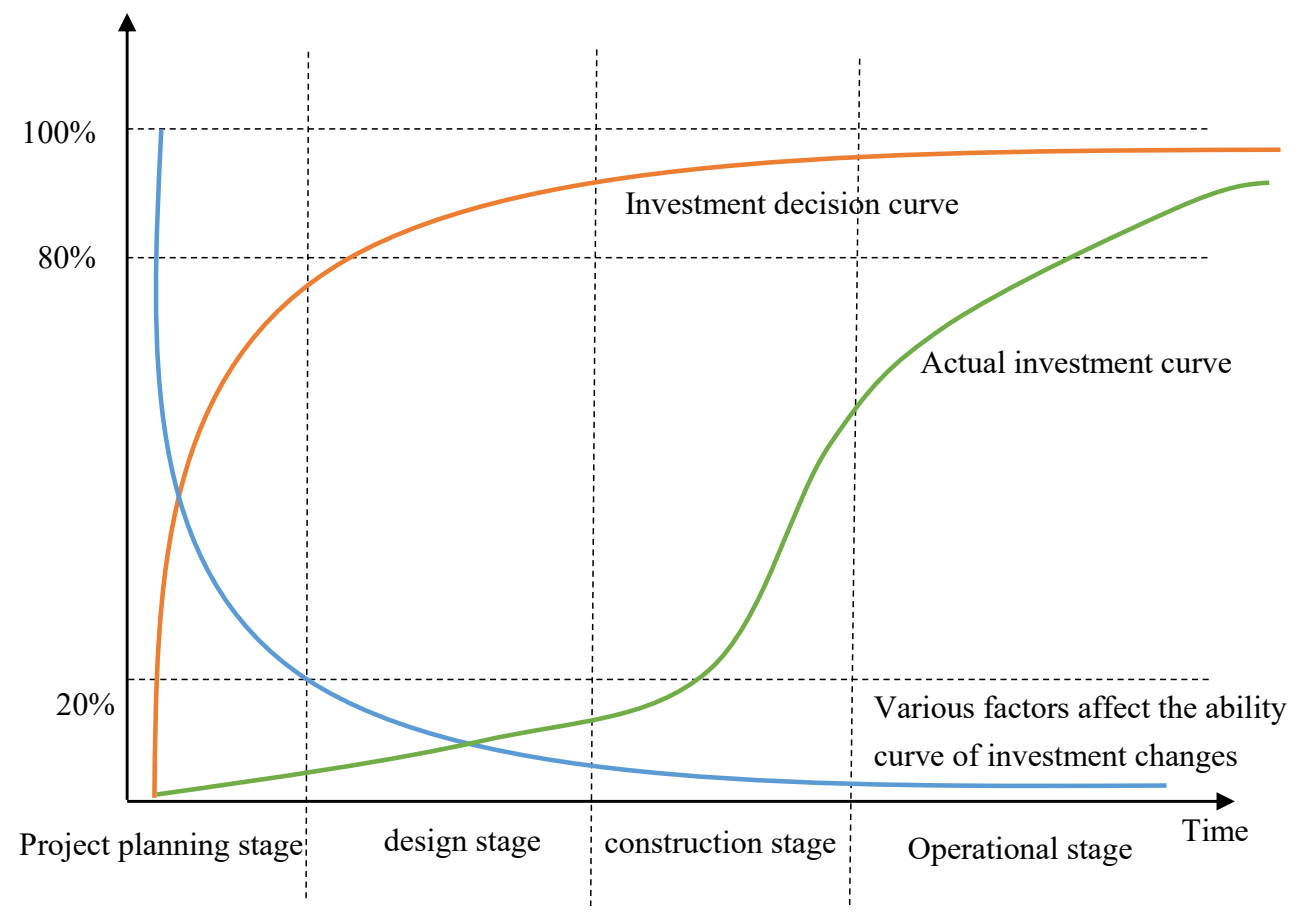

Figure 1 Curve of the impact of the project's life cycle stage on investment

For a long time, Chinese designers pay much more attention to design quality, schedule and project technology than project cost. Some designers are weak in economic concept. They consider it as their tasks to guarantee technology is feasible and quality is reliable while construction cost is none of their business but budgeters'. Owing to less economic consideration in construction drawings, mistakes, omissions as well as fat-beam and thin post often occurs in design. If things go on, it will certainly lead to big waste of national construction capitals. Therefore, we must strengthen and optimize design. Figure 2 shows the opposition and unity of quality, schedule, and investment in the process of project investment.

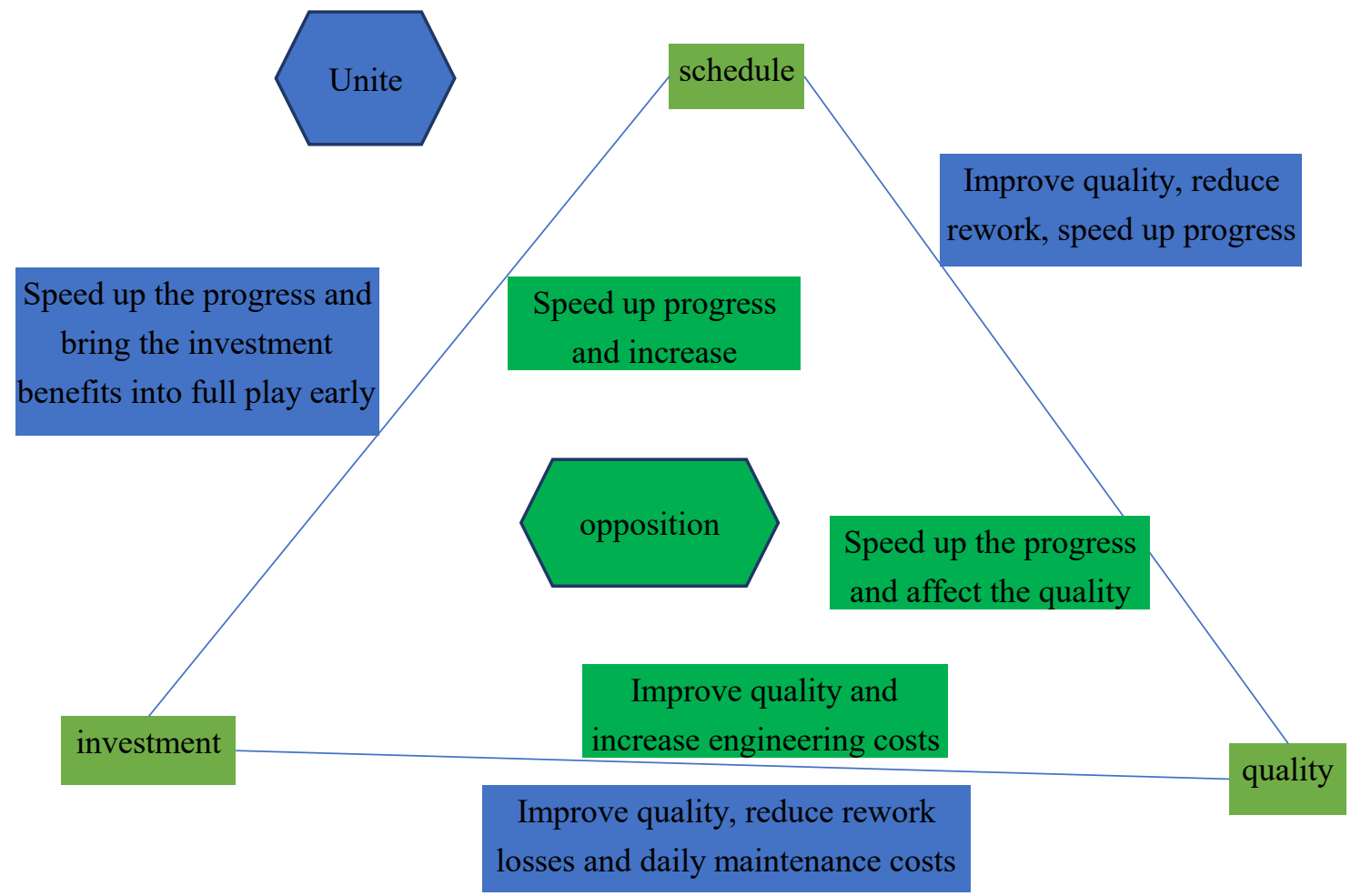

Figure 2 The opposition and unification of quality, progress, and investment in the process of project investment 
During design, it is important to apply scientific theories and economic consideration in selecting designs. That is, it is important to testify not only technically but also from the angle of connecting technology with economy. When comparing designs, cost-benefit method is recommended. In addition to project structure and functions, it is better to select designs on the basis of economic indexes. Once the design is determined, the value engineering method is recommended to lower construction costs. The value engineering is a modern scientific method which is to analyze the product functions to realize necessary functions and maximize its values at the lowest total cost. This method is effective to decrease project investment and achieve the best economic benefit, social benefit and environmental benefit by refining functions, omitting unnecessary functions and focusing on controlling high-cost functions.

\section{3. improving bidding and tendering}

Bidding and tendering is a complicate competitive trading approach and a serious legal action, which requires that the bidding staff have a good command of bidding procedure, bidding technique as well as such knowledge as laws, finance, economy and foreign trade, and which needs professionals in charge or otherwise will result in legal disputes [3]. The success and effectiveness of an investment activity are affected by many social factors, including technical, economic, political and legal, management and natural factors. How to conduct scientific investigation and prediction, analysis and calculation, comparison and evaluation of these factors is a very important and very complex systematic work. The feasibility study is to carry out the technological advancement of the investment project before a large amount of investment in the project., Economic rationality, social justice and ecological adaptability analysis and comprehensive evaluation, select the scientific decision-making method of the project plan with the most comprehensive benefits of technology, economy, and society that satisfy investors. The whole process is shown in Figure 3. 


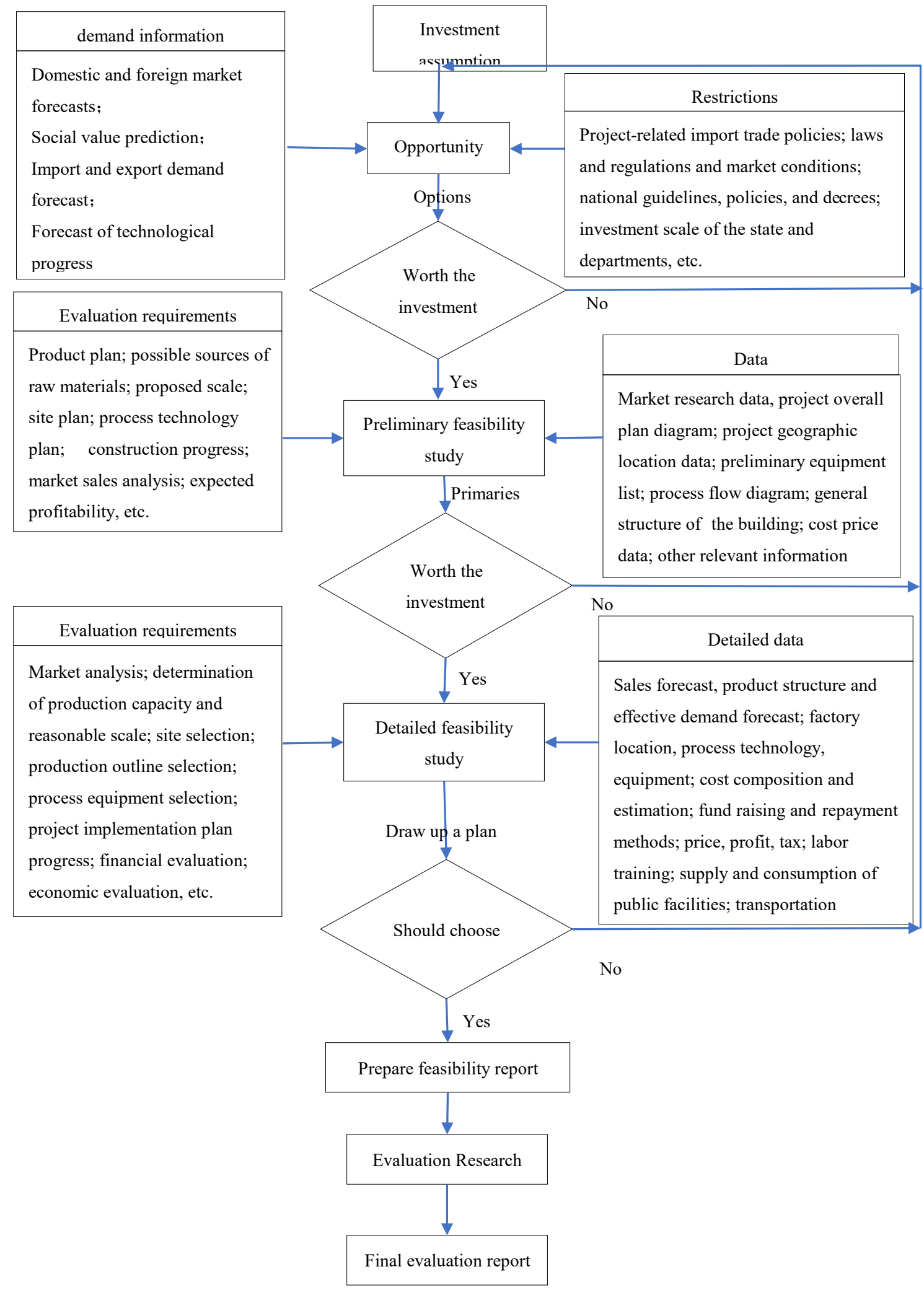

Figure 3 Feasibility study of project bidding

In all projects, there is a commission-agent relationship with the contractor. The owner entrusts the contractor to carry out the specific construction of the project. Owners also entrust bidding agencies to carry out bidding agency, and owners entrust bid evaluation experts to carry out professional work such as bid evaluation [4]. In this way, a trust-agent chain of taxpayer-government (owner)-bidding agency-bid evaluation expert-bidding company is formed among these market entities. The principal-agent relationship is shown in Table 1. 
Table 1 Principal-agent relationship in bidding

\begin{tabular}{|c|c|c|c|}
\hline $\begin{array}{l}\text { Principal-agent } \\
\text { relationship }\end{array}$ & Principal & agent & $\begin{array}{l}\text { Adverse selection and moral hazard that the agent may } \\
\text { produce }\end{array}$ \\
\hline $\begin{array}{l}\text { Taxpayers and } \\
\text { government departments }\end{array}$ & taxpayer & $\begin{array}{l}\text { Government } \\
\text { department }\end{array}$ & $\begin{array}{l}\text { One is that the project construction plan is not optimal or } \\
\text { does not conform to the viewpoint of sustainable } \\
\text { development, such as the achievement project; the other is } \\
\text { that some contractors expand the scale and raise the } \\
\text { construction standard without authorization due to the } \\
\text { non-profit nature of the construction project, such as the } \\
\text { "fishing project"; The third is the corruption and bribery of }\end{array}$ \\
\hline
\end{tabular}
some officials during the project.

Moral hazard: First, the agent changed the special purpose of the project funds without authorization, making the project unable to complete on time due to lack of funds; second, concealing the truth, cutting corners, shoddy, and $\begin{array}{lll}\begin{array}{l}\text { Owner and project } \\ \text { contractor }\end{array} & \text { owner } & \begin{array}{l}\text { Engineering } \\ \text { Contractors }\end{array}\end{array}$ failing to meet the contract quality requirements; third, the visa is false, False quotes, causing investment out of control and serious overspending.

Adverse selection: Some bidding companies with poor qualifications try to win the bid by falsely reporting their strengths when the owner cannot fully understand the contractor.

Moral hazard: First, the bidding agency will disclose information that should be kept secret, such as the base of the bid, to the corresponding bidding companies in

Owners and bidding agencies

owner Bidding agency advance; second, when setting up the bid evaluation principle, it favors certain companies and undermines the fair and just principle of bidding.

Adverse selection: Some agencies use shoddy reports to falsely report their strengths, causing owners to make mistakes in their choices.

One is that bid evaluation experts may collude with bidding companies during the bid evaluation process and give high

$\begin{array}{lll}\begin{array}{l}\text { Owners and bid } \\ \text { evaluation experts }\end{array} \quad \text { owner } & \begin{array}{l}\text { Bid evaluation } \\ \text { expert }\end{array}\end{array}$
marks to companies that are not strong; second, relative to the professionalism and complexity of the bid evaluation work, some experts did not perform in the bid evaluation process. The professionalism it deserves.

In practice, it is necessary to do as follows:

\subsection{Reasonability of bottom bidding price}

The bottom bidding price reflects the product price of construction project instead of market price. It is determined according to the national quota, fees, equipment and material price, designed construction quantity and so on. According to the law of value, when the supply exceeds the demand, that is, when the construction capacity is considered as the bottom bidding price, the price will reflect the principle of fair competition, which agrees with the basic rule of market economy. While in practice, the bottom bidding price goes far away from the value of building products, the reasons for which are: the time to compile the bottom bidding price is short; the staff to compile the price are low in quality; the construction quantity is not computed accurately; the quota and material prices are not chosen reasonably; and so on. Therefore, it is necessary to have time enough and have people with necessary qualifications to compile the bottom bidding price.

\subsection{Normalization of bidding}

Bid price is the price made by the construction enterprise itself, which reflects the enterprise's autonomous pricing right. The enterprise's autonomous pricing must be based on the enterprise's individual cost calculation, which reflects the reasonable connection of "individual labor time" and "social labor time" [5]. Meanwhile, public bids must reflect the principle of "unified quantity, directive price and competitive expenses", which requires that arbitrarily lowering direct expenses and deviating from quota pricing base be not allowed, or otherwise it will result in not only contractors' loss but also owners' loss.

\subsection{Impartiality of bid evaluating}

Bid evaluation is the key link of bidding, which must agrees with the fair principle and needs a fair and reasonable, scientific and advanced, operable method to guranttee it. Therefore, the non-normalization and non-fairness as result of competition disorder in the building markets must be banned.

\section{Scientific management}

As the socialist market economy is established, the management of building projects has been improved a lot. The practice of years has proved that the management leads to efficiency and economization, which has been realized and accepted by more and more owners and contractors who consciously put scientific management in the first place [6]. The scientific management must be 
applied throughout the entire construction period from finance at the beginning to acceptance in the end, including management of personnel, money and materials. Figure 4 shows the general scientific management system framework structure diagram.

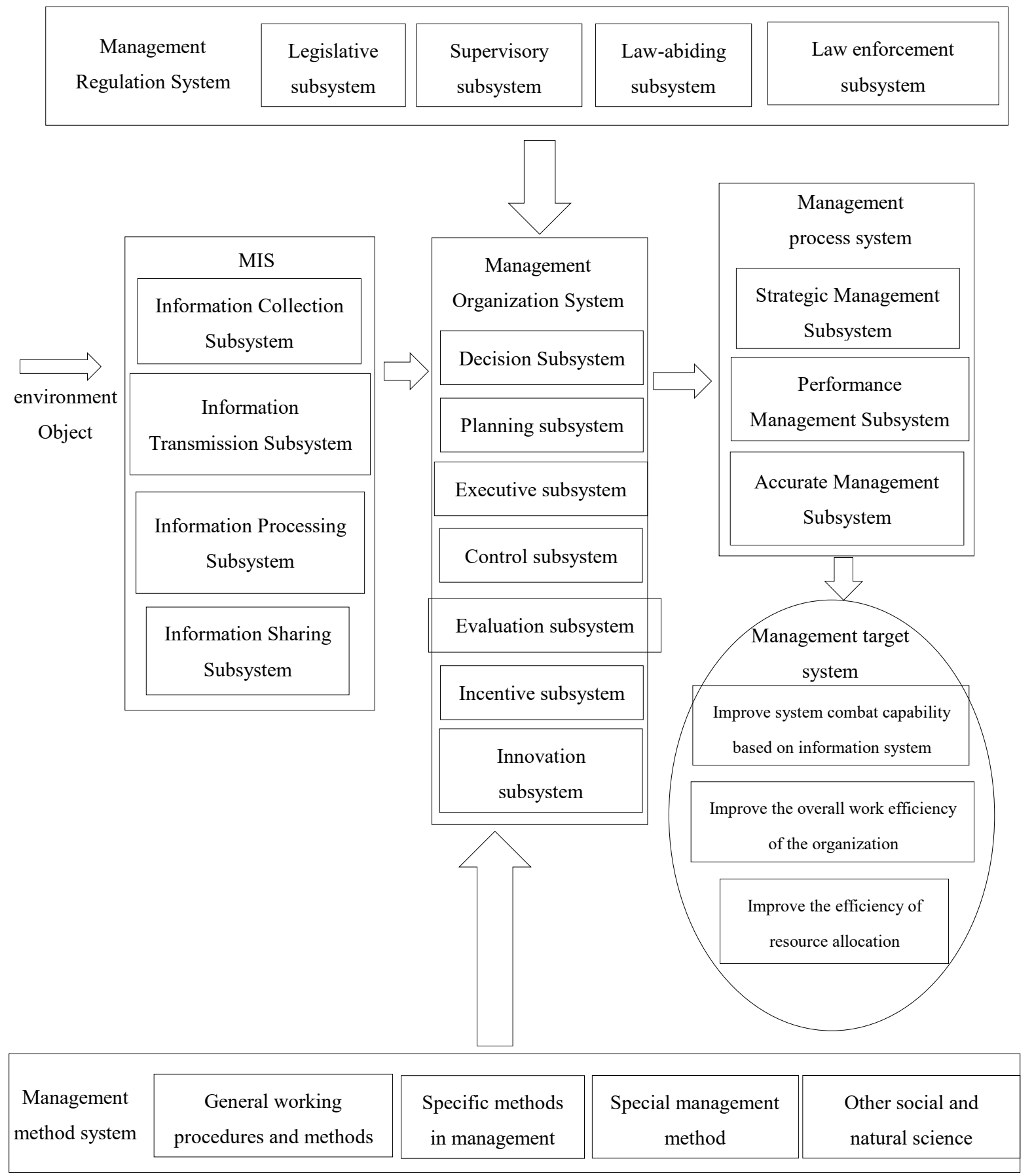

Figure 4 Framework structure diagram of general scientific management system

As result of money worship, an undesirable trend happens in building market. In order to gain high profits, some contractors use inferior materials and produce substandard goods, which result in quality accidents. Some investment out of control result from enforced idleness or rework due to poor organization and waste of personnel, money and materials. As the consciousness of owners and contractors is improved, scientific management will be an important approach to control investment.

\section{Strengthening audit}

Strengthening audit is an important measure to control investment. As shown in Figure 5, it is a schematic diagram of the whole process of audit work flow of construction projects. 


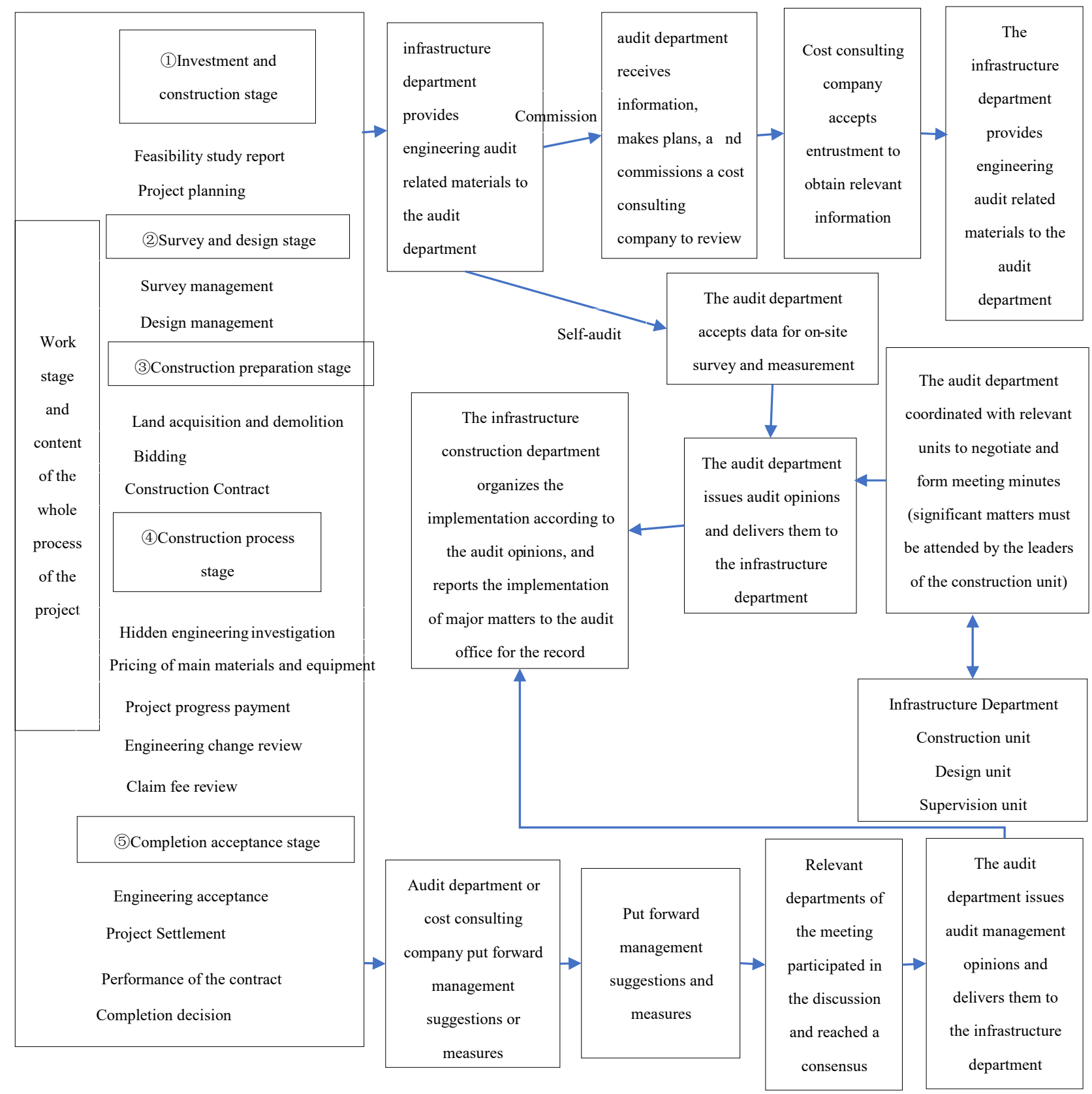

Figure 5 Schematic diagram of the whole process audit workflow of construction projects

From the beginning of the project, we should strengthen the review and audit, dynamically track the whole process of funds and use, and do a good job in controlling the early, middle and late stages of the project. There are many reasons for the "Three Excesses" of the construction project, such as in the initial stage of the project, the design did not reach the required depth, the work was rough, resulting in an increase in the amount of work in the process of project implementation or expansion of investment requirements or misappropriation. In the process of preparing estimates, budget personnel mechanically apply indicators or make improper adjustments; in the process of preparing estimates, the quota and project selection are unreasonable; the price positioning of equipment and materials is inaccurate; and there is the influence of "officer consciousness and owner thought". All of these are important factors causing investment distortion. Therefore, in the initial stage of the project, the design scheme, equipment selection, investment estimation, budget estimate, investment benefit, etc. should be reviewed. In the middle stage of the project, that is, in the implementation stage of the project, we should track and review the equipment, material orders, project budget and project progress payment. In the later stage of the project, the focus is to review the project settlement and final accounts. More specifically, the review of project budget and settlement is an important stage to control investment and improve investment efficiency. At the same time, the balance of the project can only be confirmed after the review. Since the opening of the construction market, the disputes between the 
construction units and the construction units in the project budget (settlement) methods have occurred from time to time, and sometimes the contradictions are very sharp, which requires the entrustment of the project cost intermediary agencies for reasonable price evaluation. The entrusted intermediary agencies must hold the project cost quality certificate, and those without the qualification certificate can not be entrusted. According to my practice over the years, some projects submitted for approval are subject to different procedures, and there is a phenomenon of overestimation and calculation. It is surprising that some projects are as high as $30 \%$. Only through fair evaluation of the intermediary can disputes be effectively resolved [7].

\section{Conclusion}

To sum up, the investors must double check the accuracy of budgetary estimate, the authenticity of project settlement and the reasonability of expenses. optimizing design, improving bidding and tendering, scientifically managing and strengthening audit will promote investment control. It is obvious that the analysis above is operable, its benefits are remarkable. The investment control of projects will add a bright scenery spots to the building market mechanisms.

\section{References}

1.Liu Ling. Modern Construction Management methods and Application[M]. Wuhan: Wuhan Industry Press, 2019

2.Wang Bingjie, Zhang Lei; Study on the Risk Analysis Method of Project Investment[C]. 4th International Institute of Statistics and Management Engineering Symposium (IISMES), Shandong Appl Stat Assoc, Dalian, PEOPLES R CHINA, 2011:329-333.

3. $\mathrm{Xu} \mathrm{X}$, Yang $\mathrm{Z}$, Jin $\mathrm{L}$, et al. Research on Risk Assessment of Port Project Investment and Construction[J]. Journal of Coastal Research, 2020, 115(sp1):187.

4. Momeni M A, Yaghoubi S, Aliha M. An optimal control model for analyzing quality investment in the project management[J]. Computers \& Industrial Engineering, 2019, 129(MAR.):529-544.

5.Carvallo J P, Murphy S P, Stuart E, et al. Evaluating project level investment trends for the U.S. ESCO industry: 1990-2017[J]. Energy Policy, 2019, 130:139-161.

6.Deng Fumin; Jin Yanan; Ye Meng, et al.New Fixed Assets Investment Project Environmental Performance and Influencing Factors-An Empirical Analysis in China's Optics Valley[J].INTERNATIONAL JOURNAL OF ENVIRONMENTAL RESEARCH AND PUBLIC HEALTH, 2019, 24(16).

7.Tang W, Cui Q, Zhang F, et al. Urban Rail-Transit Project Investment Benefits Based on Compound Real Options and Trapezoid Fuzzy Numbers[J].
Journal of Construction Engineering and Management, 2019, 145(1): 05018016. 1-05018016.11. 